\title{
Estimation of Global Solar Radiation, Sunshine Hour Distribution and Clearness Index in Enugu, Nigeria
}

\author{
*1,2ADENIJI, NO; ${ }^{1}$ AKINPELU, JA ; ${ }^{2}$ ADEOLA, SO ; ${ }^{3}$ ADENIJI, JO \\ ${ }^{I}$ Department of Physics and Solar Energy, Bowen University, Iwo, Osun State \\ ${ }^{2}$ Solar Energy Research and Application Centre, Iwo, Osun State \\ ${ }^{3}$ Department of Computer Science and Information Technology, Bowen University, Iwo, Osun State \\ *Corresponding Author Email: ntadeniji@gmail.com
}

\begin{abstract}
The concept of solar energy and its applications in this present day world would come to be one of the solutions to our present Nigerian problem of instability and epileptic power supply. In the study, the baseline data for mean monthly sunshine hours $(S)$ and global solar radiation $(H)$ for Enugu $\left(6.7^{\circ} \mathrm{N}, 7.6^{\circ} \mathrm{E}\right)$ were obtained from the Nigeria Metrological Agency (NIMET), Oshodi Lagos Nigeria and spanned 1996 to 2010. The data for global solar radiation were measured with a Gunn-Bellani radiometer. The average sunshine hour for the period of study was estimated to be 5.67 hours; the Angstrom constants $a$ and $b$ of Angstrom-type correlation used in estimating monthly average global solar radiation was estimated to be 0.27 and 0.58 respectively; a linear regression correlation model was developed for Enugu. The result of global solar radiation was found to be $14.44 \mathrm{MJm}^{-2} \mathrm{day}^{-1}$ thereafter subjected to statistical tests $[M B E, R M S E, M P E]$ and proved to be good estimates with previous literatures reviewed. The value of clearness index $\left(K_{T}\right)$ was estimated to range from 0.43 to 0.61 showing Enugu as so a partly clear sky city.
\end{abstract}

\section{DOI: https://dx.doi.org/10.4314/jasem.v23i2.22}

Copyright: Copyright (C) 2019 Adeniji et al. This is an open access article distributed under the Creative Commons Attribution License (CCL), which permits unrestricted use, distribution, and reproduction in any medium, provided the original work is properly cited.

Dates: Received: 16 December 2018; Revised: 20 January 2019; Accepted 29 January 2019

Keywords: Global solar radiation, Sunshine hour distribution, Clearness Index Enugu.

Solar Energy is one of the foremost and ancient sources of underutilized energy. It forms basis for the fundamental element of most fossil and renewable energies (Innocent, et al., 2015). Radiation from the sun (solar and atmospheric) has been identified as the largest renewable energy resource on earth (Gana and Akpootu, 2013). Solar radiation reaching the earth is considered to be affected by some parameters like diffusion, reflection, and so on. This radiation most time is reflected or scattered by air molecules, cloud, aerosols (dust), (Aweda et al., 2016). The global solar radiation is the sun total of all radiation reaching the earth surface i.e. it includes both the direct and the diffused solar radiation reaching the earth surface measured at any location. It has been established that sunshine duration has direct correlation with global solar radiation (Okonkwo, 2014). The application/utilization of renewable energy resources has increased largely in recent times owing to the ever increasing need for electrical/thermal energy, the limited fossil fuel resources needed for the generation of conventional electrical power, and the global environmental concerns over the use of fossil fuels (Sanusi and Abisoye, 2013). The over dependency of

*Corresponding Author Email: ntadeniji@gmail.com our present day Nigeria on hydro power generation, transmission and distribution of electricity has failed to satisfy her citizen's demands for an uninterruptable power supply hence, the need to search and research into other forms of renewable energy sources. The estimation of the clear sky irradiance components of solar radiation is very important in many solar energy applications (systems design and simulation, control process of the accuracy of radiometers, data quality control, gaps filling process, etc.), as well as in routine engineering practice (e.g., the peak cooling load of buildings is determined for a hot, cloudless, summer day.) (Islahi, et al., 2015). This study seeks to estimate the global solar radiation and give a critical look at the sunshine hour distribution in Enugu for a period of 15 calendar years.

\section{MATERIALS AND METHODS}

In the study, the baseline data for mean monthly sunshine hours $(S)$ and global solar radiation $(H)$ for Enugu $\left(6.7^{0} \mathrm{~N}, 7.6^{0} \mathrm{E}\right)$ were obtained from the Nigeria Metrological Agency (NIMET), Oshodi Lagos Nigeria and spanned 1996 to 2010 . The yearly average of each parameter was computed from which the 
monthly average of fifteen years data was obtained for Enugu.

The results obtained from this were used to study the trends of sunshine duration and global solar radiation in Enugu. The regression coefficients $a$ and $b$, the Monthly Average Daily Global Radiation $\left(\mathrm{kW} / \mathrm{m}^{2}\right) H$ , the Monthly Extraterrestrial Solar Radiation $\left(\mathrm{kW} / \mathrm{m}^{2}\right)$ $H_{0}$, the Sunset Hour Angle $w_{s}$, the Solar Declination Angle $\delta$ and the monthly average of the maximum possible daily hours of bright sunshine $S_{0}$, $\left[H, H_{0}, \frac{H}{H_{0}}, w_{s}, S_{0}, \delta\right]$ were also calculated by means of simulation of the corresponding equations into Java program compatible with netbeans which served as a calculator for the parameters. Graphical analysis were also exploited by plotting graphs of monthly mean estimated and calculated global solar radiation, mean monthly sunshine hour data and mean yearly Sunshine hour data. This was done in order to make easy for the comparison of the sunshine duration and global solar radiation for Enugu. The original Angstrom-type regression equation that relates monthly average daily radiation to clear day radiation at any station and average fraction of possible sunshine hours:

$$
\frac{\bar{H}}{\bar{H}_{c}}=a^{\prime}+b^{\prime} \frac{\bar{n}}{\bar{N}}
$$

Where $\bar{H}=$ the monthly average of daily solar radiation on a horizontal surface; $\bar{H}_{c}=$ the average clear sky daily solar radiation for the location and month; $a^{\prime}, b^{\prime}=$ empirical constants; $\bar{n}=$ monthly

average daily hours of bright sunshine; $\bar{N}=$ monthly average of the maximum possible daily hours of bright sunshine.

Equation (1) has being modified to be based on extraterrestrial radiation on horizontal surface rather than on clear day radiation and given as equations (2a) and $(2 b)$ :

$$
\begin{aligned}
& \frac{H}{H_{0}}=\left(a+b \frac{S}{S_{0}}\right) \\
& H=H_{0}\left(a+b \frac{S}{S_{0}}\right)
\end{aligned}
$$

Where: $H_{0}$ is the radiation outside of the atmosphere $a=-0.110+0.235 \cos (\phi)+0.323\left(\frac{S}{S_{0}}\right)$ subject to latitude of the location where $\mathrm{a}$ and $\mathrm{b}$ are

$b=1.449-0.553 \cos (\phi)-0.694\left(\frac{S}{S_{0}}\right)$

Where $S$ monthly average daily hours of bright sunshine and $S_{0}$ monthly average of the maximum possible daily hours of bright sunshine.

$S_{0}=\frac{2}{15} \omega_{s}$

$\frac{H}{H_{0}}$ gives the clearness index over a particular location and denoted by $K_{T}$

$H_{0}=\frac{24 \times 3600 G_{s c}}{\pi}\left[1+0.033 \cos \left(\frac{360 n}{365}\right)\right] \times\left[\cos \phi \cos \delta \sin \omega_{s}+\frac{2 \pi \omega_{s}}{360} \sin \phi \sin \delta\right]$

Where $w_{s}=\cos ^{-1}(-\tan \phi \tan \delta)$ and $\delta=23.45 \sin \left(360 \frac{284+n}{365}\right)$

This test helps to calculate the error or the deviation of the calculated value from the measured value and provides information on long-term performance. A low Mean bias error value is desired. A negative value gives the average amount of underestimation in the calculated value.

$M B E=\frac{1}{n} \sum_{1}^{n}\left(H_{c a l}-H_{\text {meas }}\right)$
The value of Root Mean Square Error is always positive, representing zero in the ideal case. The normalized root mean square error gives information on the short term performance of the correlations by allowing a term by term comparison of the actual deviation between the predicted and measured values. The smaller the value, the better the correlation (Namrata, et al., 2012) 


$$
R M S E=\left[\frac{1}{2} \sum_{1}^{n}\left(H_{\text {cal }}-H_{\text {meas }}\right)^{2}\right]^{1 / 2}
$$

The Mean Percentage Error is one of the measures used to evaluate forecasts using forecast errors. Forecast error is defined as actual observation minus forecast. The mean percentage error is the average or mean of all the percentage errors. A percentage error between $-10 \%$ and $+10 \%$ is considered acceptable (Muzathik,et al., 2011).

$$
\operatorname{MPE}(\%)=\frac{1}{n} \sum_{1}^{n}\left(\frac{\left(H_{c a l}-H_{\text {meas }}\right)}{H_{\text {meas }}}\right) \times 100
$$

\section{RESULTS AND DISCUSSION}

The sunshine hour data for Enugu (South-Eastern) Nigerian were optioned and the following figures were generated by means of calculations.

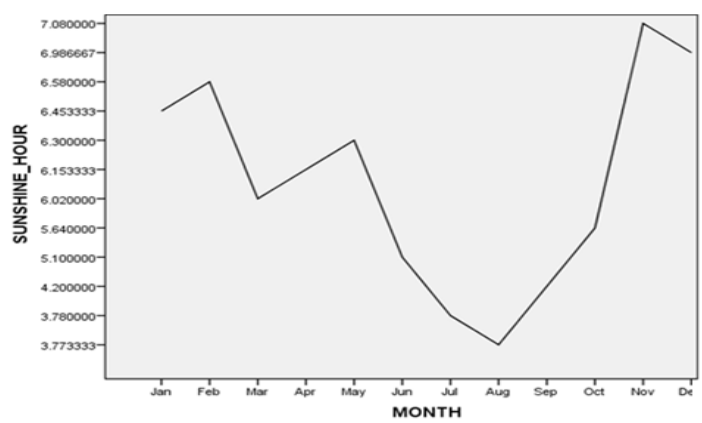

Fig 1: Yearly average mean Monthly sunshine hour distribution for Enugu from 1996 to 2010

Mean Monthly sunshine hour for Enugu happens to be highest in the month of November and lowest in the month of August as reported by Figure 1

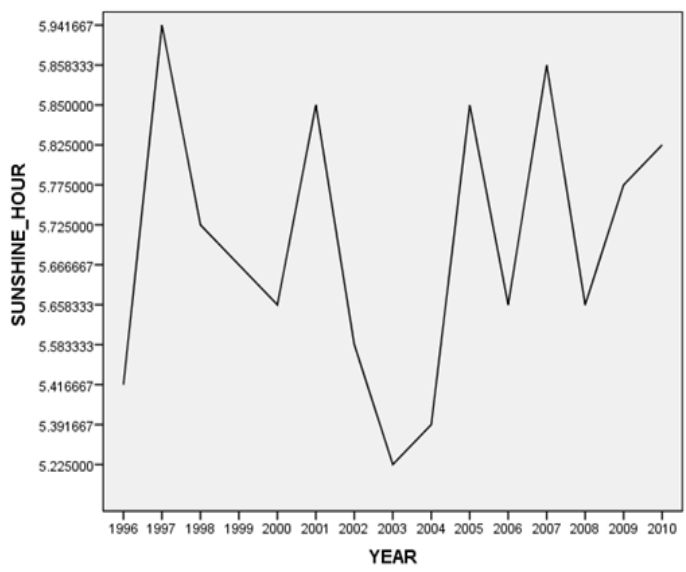

Fig 2: Mean Sunshine Hour for each year of study in Enugu.

Figure 2 shows the year 2003 had the least sunshine hour recorded between 1996 and 2010 while 1997 can be seen to have the highest value of sunshine hour in Enugu.

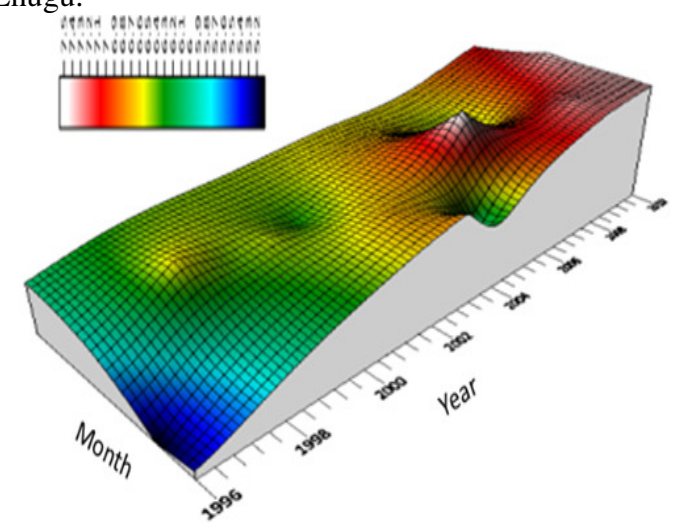

Fig 3: Distribution of Sunshine Hour for Enugu from 1996 to 2010

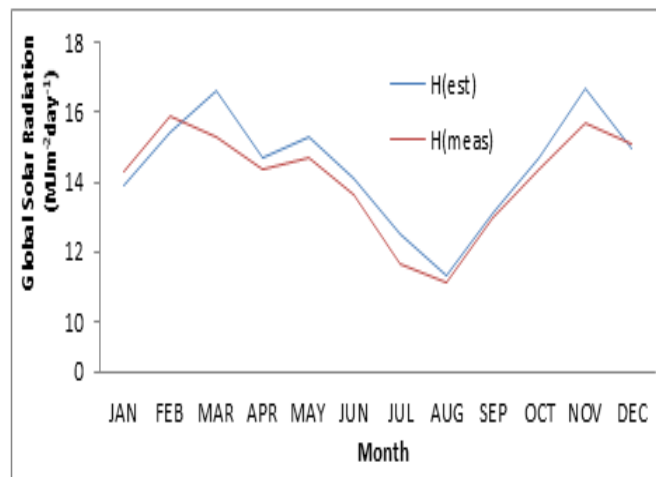

Fig 4: Monthly Estimated and Measured Global Solar Radiation for Enugu (1996 - 2010).

The colour coding for the distribution of sunshine hour in Enugu from 1996 to 2010 could be seen to range from deep blue colouration representing the least duration of sunshine to green indicating midpoint between the maximum and minimum sunshine duration with white colour as maximum sunshine duration for the study. The monthly distribution is shown along the $\mathrm{z}$ axis while the yearly distribution is on the $\mathrm{x}$ - axis of the figure 3 . The Early part of 1996 say January to March showed a low sunshine hour measurement as shown in figure 3 this could be attributed to scattering/reflection of solar radiation by dust. Consequently, the distribution of sunshine hour for Enugu improved along the year 2002 up to 2010 for which the study is carried out. The monthly distribution is shown along the $\mathrm{z}$ axis while the yearly distribution is on the $\mathrm{x}$ - axis of the figure 3. January for the following years of 2005, 2006, 2007, 2008, 2009, and 2010 showed values of sunshine hour for 7 to 7.8 
global solar radiation using four sunshine based models in

Kebbi, North-Western, Nigeria. Adv. Sci. Res. 4(5), 409-421.

Innocent, A. J.; Jacob, O. E.; Chibuzo, G. C.; James, I.; Odeh, D. O. (2015). Estimation of Global Solar Radiation in Gusau, Nigeria. Inter. J. Res. Engineer. Technol. 3(2), 27-32.

Islahi, A.; Shakil, S.; Hamed, M. (2015). Hottel's Clear Day Model for a typical arid city - Jeddah. International J. Engineer. Sci. Invent. 4(6), 3237.

Muzathik, A.M.; Nik, W.B.W.; Ibrahim, M.Z.; K.B. Samo, K. S.; Alghoul M.A., (2011) Daily global solar radiation estimate based on sunshine hours.
Inter. J. Mech. Mat. Engineer. 6(1), 75-80

Namrata, K.; Sharma, S.P. ; Saksena, S.B.L., (2012).Comparison of Estimated Daily Global Solar Radiation Using Different Empirical Models. Inter. J. Sci. Adv. Technol. 2(4), 75-80.

Okonkwo, G. N. (2014). Relationship between Global Solar Radiation and Sunshine Hour Duration for Bida in Nigeria. Inter. J. Renewable. Sustainable Energy. 3(2), 43-46.

Sanusi, Y. K.; Abisoye, S. G. (2013). Estimation of Diffuse Solar Radiation in Lagos. In 2nd International Conference on Chemical, Environment and Biological Sciences, Lagos., 6 9. 